\title{
Osmotic dehydration of eggplant, carrot and beetroot slices: Effect of vacuum on phenolic acid composition
}

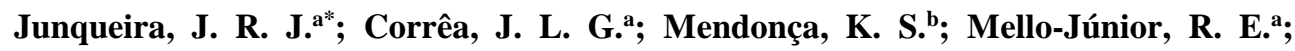
Carvalho, L. B. ${ }^{\text {a }}$

${ }^{\text {a }}$ Department of Food Science. Federal University of Lavras, Lavras, Brazil.

${ }^{\mathrm{b}}$ Department of Agrarian Science. Federal Institute of Education, Science and Technology of Minas Gerais, Bambuí, Brazil.

*E-mail of the corresponding author: jrenatojesus@hotmail.com

\begin{abstract}
The aim of this work was to evaluate the influence of vacuum application on the phenolic acid content of osmodehydrated eggplant, carrot and beetroot samples. The contents of catechins and chlorogenic acid were determined by HPLC analysis. Changes in the contents of phenolic acids after the osmotic processes were observed. It was found a reduction in catechins and chlorogenic acids, probable due to the migration and degradation losses. In a general way, the vacuum reduced the catechin and chlorogenic acid contents, compared to the osmotic dehydration at atmospheric pressure.
\end{abstract}

Keywords: Pulsed vacuum osmotic dehydration; chlorogenic acid; catechins. 


\section{Introduction}

The osmotic dehydration (OD) is a technique that provides partial water removal from a food product, with low energy consumption by been carried out at room or moderate temperatures [1]. It is based on the immersion of pieces of fresh fruits or vegetables in a hypertonic solution. The process involves simultaneous counter-current water diffusion from the food to the solution and solute diffusion into the food, under the influence of osmotic pressure gradient $[\underline{2,3}]$. It is considered a pretreatment to many processes and preserves physical, chemical and sensorial characteristics of food with few changes on its integrity $[\underline{4,5}]$.

A mass transfer rate increase can be achieved with the vacuum application in the beggining of the OD, in a process presented as pulsed vacuum osmotic dehydration (PVOD) [ 6 ]. The reduction in the pressure causes liberation of the ocluded gases in the pores of the fruit and vegetables making them expelled, due to the action of hydrodynamic mechanisms (HDM) enhanced by pressure difference, increasing the surface area for mass transfer [7-9].

The PVOD process is related to the intensification of water loss and solid uptake, compared with OD. Besides this two mass fluxes, the lixiviation of some nutrients affect qualitatively the nutritional and functional properties of the food subjected to this process [6-8].

As the water is removed, some water soluble constituints, as vitamins and phenolic acids are lixiviated, implying in significative nutritional losses [10]. The vegetables are source of bioactive compounds, among them, the phenolic acids. They confer antioxidant properties and are therefore indicated for the treatment and prevention of cancer, cardiovascular disease and other diseases [11]. This work aimed to evaluate the effect of different vacuum pressures applied in the OD of eggplant, carrot and beetroot slices in the phenolic acid content.

\section{Materials and Methods}

\subsection{Sample and osmotic solution preparation}

Fresh eggplants (Solanum melongena L.), carrots (Daucus carota L.) and beetroots (Beta vulgaricus L.) were purchased in a local market (Lavras, MG, Brazil) and stored in a refrigerator at $8 \pm 1{ }^{\circ} \mathrm{C}$ before the experiments.

All of the vegetables were washed with tap water, peeled and sliced (2.00 cm length $\mathrm{x} 2.00$ cm width $x 0.40 \pm 0.03 \mathrm{~cm}$ thickness) using a stainless steel mold. The ternary osmotic solution was prepared with distilled water, sucrose (40 kg $100 \mathrm{~kg}^{-1}$ (w/w)) and sodium chloride (10 kg $100 \mathrm{~kg}^{-1}$ (w/w)). 


\subsection{Osmotic processes}

The osmotic processes were performed in an osmotic dehydrator with temperature and inner pressure control (Fig 1) []]

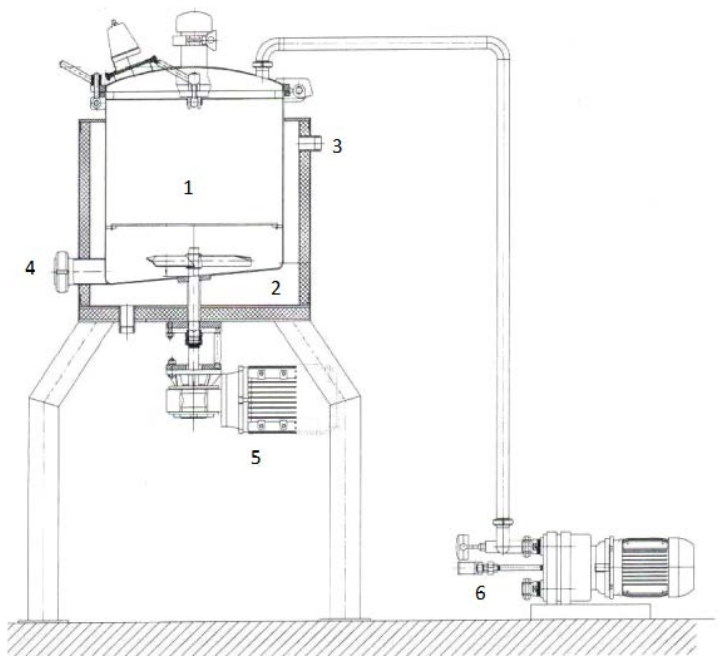

Fig. 1 Vacuum pulse osmotic dehydration device. 1 - inside osmotic dehydrator, 2 - thermal jack; 3 - outlet of thermal jacked section 4 - output to remove osmotic solution, 5 - motor coupled to the blade inside dehydrator to promote agitation; 6 - vacuum pump.

The experiments were conducted in three different conditions and the total time of the osmotic process was $300 \mathrm{~min}$. Part of this time, in the beginning of the process (10 min), could involve vacuum pulse application, followed by atmospheric pressure restoration (755 $\mathrm{mmHg}$ ). The treatments are presented in the Table 1.

Table 1. Experimental conditions

\begin{tabular}{|c|c|}
\hline Treatment & Conditions \\
\hline 1 & OD (absolute pressure $=755 \mathrm{mmHg}$ ) \\
\hline 2 & PVOD (absolute pressure $=455 \mathrm{mmHg}$ ) \\
\hline 3 & PVOD (absolute pressure $=155 \mathrm{mmHg}$ ) \\
\hline
\end{tabular}

The processes temperature was set at $35 \pm 1{ }^{\circ} \mathrm{C}$ and the ratio of solution to vegetable was $1: 10(\mathrm{w} / \mathrm{w})$. After the osmotic processes, the samples were removed from the solution and immersed in a bath of cold distilled water during $10 \mathrm{~s}$ to stop the osmosis and to remove 
solution excess. The surface of the samples was gently wiped with absorbent paper, and they were weighed and submitted to moisture content determination [12] and cromatography analyzes. All the experiments were performed in four replicates.

\subsection{Chromatography analyses}

The polyphenols for high performance liquid efficiency chromatography (HPLC) were extracted using $2.5 \mathrm{~g}$ of pulp and $20 \mathrm{~mL}$ solution containing $70 \%$ methanol in water (v/v) [13]. Briefly, the samples were homogenized and placed in an ultrasonic bath at $20{ }^{\circ} \mathrm{C}$ for $60 \mathrm{~min}$. The extracts were centrifuged at $1400 \mathrm{~g}$ for $15 \mathrm{~min}$ at $4{ }^{\circ} \mathrm{C}$ and filtered through Whatman $\mathrm{n}^{\circ} 2$ filter paper. The extracts were again filtered with regenerated cellulose filters $0.45 \mu \mathrm{m}$ (Millipore, Bedford, MA, USA) and stored at $-18^{\circ} \mathrm{C}$ until the analyses.

The chromatographic analyses were performed using an Ascentis C18 5-lm (250 mm x 4 $\mathrm{mm}$ ) column. The mobile phase consisted of $2 \%(\mathrm{v} / \mathrm{v})$ acetic acid in water (mobile phase A) and 70:28:2 methanol/water/acetic acid (mobile phase B), set to a flow rate of $1.0 \mathrm{~mL}$ min1 and conducted using a gradient elution programme and a $65 \mathrm{~min}$ run time. The injection volume was $20 \mu \mathrm{L}$. Analyses were performed at $15^{\circ} \mathrm{C}$. The phenolic compounds generated a UV-Vis spectral result in the HPLC chromatogram at $280 \mathrm{~nm}$. Quantitative determination of compounds was conducted by comparison with dose-response curves based on $\mathrm{m} / \mathrm{z}$ data from authentic standards of individual polyphenols [14]. The results of three replicates were expressed as mg $100 \mathrm{~g}^{-1}$ (d. b.).

\subsection{Statistical analyses}

The results were subjected to analysis of variance (ANOVA) using software STATISTICA $8.0^{\circledR}$ (Statsoft, Tulsa, USA). Tukey’s test was used to compare means at the $5 \%$ significance level $(\mathrm{p}<0.05)$.

\section{Results and discussion}

For the identified phenolic acids, significant differences after the osmotic processes $(\mathrm{p} \leq$ 0.05 ) have been found (Table 2) for all the vegetables.

According to the Table 2, catechin was identified in all the different vegetables, with higher concentration in beetroot samples, followed by carrot and eggplant. The chlorogenic acid (5-O-caffeoyl-quinic acid; CQA) was observed only in the eggplant samples.

A reduction in the catechin content was observed for all osmodehydrated vegetables (Table

2). This occurred probable due to the migration and lixiviation losses, that are related with 
the mass transfer during the osmotic dehydration. It is well known that as the water is removed from the products (due to the osmotic pressure gradient between the material and the osmotic solution), some water soluble compounds also migrate from the cell tissue to the liquid media [15-17]. For the beetroot samples, the catechins were lightly preserved in the treatment 2 (PVOD with absolute pressure of $455 \mathrm{mmHg}$ ) (Table 2).

Table 2. Phenolic acid content of fresh and osmodehydrated vegetables [mg $100 \mathrm{~g}^{-1}$ ] (d.b.)

\begin{tabular}{llllc}
\multicolumn{1}{c}{ Treatments } & Fresh & $\mathbf{1}$ & $\mathbf{2}$ & 3 \\
& \multicolumn{5}{c}{ Catechin } \\
\hline Eggplant & $21.26 \pm 1.66^{\mathrm{a}}$ & $12.22 \pm 1.24^{\mathrm{b}}$ & $13.42 \pm 0.61^{\mathrm{b}}$ & $2.40 \pm 0.15^{\mathrm{c}}$ \\
Carrot & $36.89 \pm 2.89^{\mathrm{a}}$ & $28.72 \pm 1.44^{\mathrm{b}}$ & $31.42 \pm 2.06^{\mathrm{b}}$ & $21.09 \pm 0.10^{\mathrm{c}}$ \\
Beetroot & $215.48 \pm 4.31^{\mathrm{a}}$ & $90.17 \pm 3.93^{\mathrm{c}}$ & $116.67 \pm 4.20^{\mathrm{b}}$ & $75.17 \pm 2.88^{\mathrm{d}}$ \\
\hline \multicolumn{5}{c}{ Chlorogenic acid $^{\mathrm{y}}$} \\
\hline Eggplant & $367.71 \pm 11.43^{\mathrm{a}}$ & $219.07 \pm 11.42^{\mathrm{b}}$ & $183.17 \pm 8.29^{\mathrm{c}}$ & $82.92 \pm 3.62^{\mathrm{d}}$ \\
\hline
\end{tabular}

Average value \pm standard deviation. Mean followed by different letters in the row differs significantly ( $p<0.05$ ), according to Tukey's test.

Comparing the catechin content in fresh and osmodehydrated blueberries [18] also observed significant reduction in its retention. They concluded that the vacuum application reduced the catechin content, compared with OD treatment.

Studies indicate that the main phenolic compound in the eggplant is the chlorogenic acid [19]. Its content was reduced in PVOD treatments by 50-75 \% (Table 2). This phenolic compound is a hydroxycinnamic acid derivative, and such a reduction occured probable due to the mass transfer intensification when the vacuum was applied [20-22]. Nevertheless, the losses of this polyphenol acid was also observed in OD treatment. This indicates that besides the losses by lixiviation, some oxidative and hydrolytic modifications were observed.

According to the Table 2, the vacuum application implied in a pronounced phenolic reduction, compared to the OD. The retention in phenolic compounds are desirable, once they present a wide range of biological activities, related to the risk decrease of heart and neurodegenerative diseases, and certain forms of cancers [를. 


\section{Conclusions}

The osmotic dehydration of vegetables (eggplant, carrot and beetroot) was achieved in different conditions. It was observed changes in the phenolic acid contents after the osmotic processes. It was found a reduction in catechins and chlorogenic acids, probable due to the migration and degradation losses. In a general way, the vacuum reduced the catechin and chlorogenic acid contents, compared to the OD. It was concluded that the osmotic process (under vacuum or atmospheric pressure) reduces the analyzed phenolic acid content.

\section{Acknowledgements}

The authors gratefully acknowledge CAPES (Coordination for the Improvement of Higher Education Personnel), CNPq (National Council for Scientific and Technological Development) and FAPEMIG (State of Minas Gerais Research Foundation).

\section{References}

[1] Mendonça, K.S.D.; Corrêa, J.L.G.; Junqueira, J.R.J.; de Angelis Pereira, M.C.; Cirillo, M.A. Mass transfer kinetics of the osmotic dehydration of yacon slices with polyols. Journal of Food Processing and Preservation 2017, 41, 1-8.

[2] Akbarian, M.; Moayedi, F.; Ghasemkhani, N.; Ghaseminezhad, A. Impact of antioxidant edible coatings and osmotic dehydration on shrinkage and colour of " Quince ” dried by hot air. International Journal of Bioscience 2014, 4(1), 27-33.

[3] Vieira, G.S.; Pereira, L.M.; Hubinger, M.D. Optimisation of osmotic dehydration process of guavas by response surface methodology and desirability function. International Journal of Food Science and Technology 2012, 47(1), 132-140.

[4] Abbasi Souraki, B.; Ghaffari, A.; Bayat, Y. Mathematical modeling of moisture and solute diffusion in the cylindrical green bean during osmotic dehydration in salt solution. Food and Bioproducts Processing 2012, 90(1), 64-71.

[5] Corrêa, J.L.G.; Ernesto, D.B.; Alves, J.G.L.F.; Andrade, R.S. Optimisation of vacuum pulse osmotic dehydration of blanched pumpkin. International Journal of Food Science and Technology 2014, 49, 2008-2014.

[6] Fante, C.; Corrêa, J.; Natividade, M.; Lima, J.; Lima, L. Drying of plums (Prunus sp, c.v Gulfblaze) treated with $\mathrm{KCl}$ in the field and subjected to pulsed vacuum osmotic dehydration. International Journal of Food Science and Technology 2011, 46, 10801085 .

[7] Fito, P. Modelling of vacuum osmotic dehydration of food. Journal of Food Engineering 1994, 22(1-4), 313-328.

[8] Viana, A.D.; Corrêa, J.L.G.; Justus, A. Optimisation of the pulsed vacuum osmotic 
dehydration of cladodes of fodder palm. International Journal of Food Science and Technology 2014, 49, 726-732.

[9] Oliveira, L.F.; Mendonça, K.S.; Corrêa, J.L.G.; Junqueira, J.R.J.; Justus, A. Efeito de ondas ultrassônicas e de pulso de vácuo nos parâmetros de qualidade peras osmoticamente desidratadas. Caderno de Ciências Agrárias 2016, 8(1), 38-48.

[10] Bera, D.; Roy, L. Osmotic dehydration of litchi using sucrose solution : Effect of mass transfer. Journal of Food Processing and Technology 2015, 6(7), 1-7.

[11] Soares, S.E. Ácidos Fenólicos Como Antioxidantes. Revista da Nutrição 2002, 15(1),71-81.

[12] AOAC. Official methods of analysis of the association of official analytical chemist 2010, 17th edition, Washington, DC.

[13] Ramaiya, S.D.; Bujang, J.S.; Zakaria, M.H.; King, W.S.; Shaffiq Sahrir, M.A. Sugars, ascorbic acid, total phenolic content and total antioxidant activity in passion fruit (Passiflora) cultivars. Journal of the Science and Food Agricultural 2013, 93(5), 11981205.

[14] Gonçalves, G.A.S.; Resende, N.S.; Carvalho, E.E.N.; Resende, J.V.; Vilas Boas, E.V.B. Effect of pasteurisation and freezing method on bioactive compounds and antioxidant activity of strawberry pulp. International Journal of Food Science and Nutrition 2017, 68(6),682-694.

[15] Corrêa, J.L.G.; Rasia, M.C.; Garcia-Perez, J.V.; Mulet, A, Jesus Junqueira, J.R.; Cárcel, J.A. Use of ultrasound in the distilled water pretreament and convective drying of pineapple. Drying and Energy Technologies 2015.

[16] Corrêa, J.L.G.; Justus, A.; Oliveira, L.F.; Alves, G.E. Osmotic dehydration of tomato assisted by ultrasound: evaluation of the liquid media on mass transfer and product quality. International Journal of Food Engineering 2015, 11(4), 505-516.

[17] Ahmed, I.; Qazi, I.M.; Jamal, S. Developments in osmotic dehydration technique for the preservation of fruits and vegetables. Innovative Food Science and Emerging Technologies 2016, 34, 29-43.

[18] Moreno, J.; Gonzales, M.; Zúñiga, P.; Petzold, G.; Mella, K.; Muñoz, O. Ohmic heating and pulsed vacuum effect on dehydration processes and polyphenol component retention of osmodehydrated blueberries (cv. Tifblue). Innovative Food Science and Emerging Technologies 2016, 36, 112-119.

[19] Singh, A.P.; Luthria, D.; Wilson, T.; Vorsa, N.; Singh, V.; Banuelos, G.S. Chlorogenic acid retention in white and purple eggplant after processing and cooking. Food Chemistry 2015, 64(3), 802-808.

[20] Moraga, M.J.; Moraga, G.; Fito, P.J.; Martínez-Navarrete, N. Effect of vacuum impregnation with calcium lactate on the osmotic dehydration kinetics and quality of osmodehydrated grapefruit. Journal of Food Engineering 2009, 90 (3), 372-379.

[21] Corrêa, J.L.G.; Ernesto, D.B.; Mendonça, K.S. Pulsed vacuum osmotic dehydration of tomatoes: Sodium incorporation reduction and kinetics modeling. LWT - Food 
Science and Technology 2016, 71, 17-24.

[22] Oliveira, L.F.; Corrêa, J.L.G.; Angelis Pereira, M.C.; Ramos, A.L.A.; Vilela, M.B. Osmotic dehydration of yacon (Smallanthus sonchifolius): Optimization for fructan retention. LWT - Food Science and Technology 2016, 71, 77-87.

[23] Luthria, D.; Singh, A.P.; Wilson, T.; Vorsa, N.; Banuelos, G.S.; Vinyard, B.T. Influence of conventional and organic agricultural practices on the phenolic content in eggplant pulp: Plant-to-plant variation. Food Chemistry 2010, 121(2),406-411. 